\title{
Solitary Rectal Ulcer Syndrome: A Narrative Review
}

\author{
Anahita Sadeghi ${ }^{1}$, Mohammad Biglari ${ }^{2}$, Mojgan Forootan ${ }^{3,}$, Peyman Adibi ${ }^{4}$
}

1. Digestive Disease Research Institute, Shariati Hospital, Tehran University of Medical Sciences, Tehran, Iran

2. Department of Internal Medicine, Shariati Hospital, Tehran University of Medical Sciences, Tehran, Iran

3. Department of Gastroenterology, Gastrointestinal and Liver Diseases Research Center (RCGLD), Shahid Beheshti University of Medical Sciences, Tehran, Iran

4. Department of Internal Medicine, Isfahan University of Medical Sciences, Isfahan, Iran

\footnotetext{
* Corresponding Author:

Mojgan Forootan, MD

Associate Professor, Department of Gastroenterology, Gastrointestinal and Liver Diseases Research Center (RCGLD), Shahid Beheshti University of Medical Sciences, Taleghani Educational Hospital, Tehran, Iran

Telefax: + 982122432560

Email: mfrootan@sbmu.ac.ir

Received: 10 Feb. 2019

Accepted: 16 Jun. 2019
}

\section{ABSTRACT}

Solitary rectal ulcer syndrome is a multifactorial pathology, which entails a variety of clinical, histologic and endoscopic aspects that needs step-wise logical approach for management especially in relapsing refractory cases. Apart from the diagnostic dilemma that may be faced due to similarities of presentation with inflammatory bowel diseases or colorectal neoplastic lesions, the syndrome also overlaps with dyssynergic defecation syndrome, health anxiety disorder, obsessive compulsive disorder, and latent mucosal rectal prolapse, a systematic composite treatment modality including psychological, pharmacological, physiological and possibly surgical interventions are sometimes essential. Selecting appropriate treatment in this condition not only affects clinical outcome but also patients' experience and further stigma of SRUS life-long. In this review, we will discuss the detailed pathophysiology, diagnostic and therapeutic approaches in dealing with solitary rectal ulcer syndrome.

\section{KEYWORDS}

Solitary rectal ulcer syndrome, Inflammatory bowel diseases, Colorectal neoplastic lesions

Please cite this paper as:

Sadeghi A, Biglari M, Forootan M, Adibi P. Solitary rectal ulcer syndrome: A narrative review. Middle East J Dig Dis 2019;11:129-134. doi:10.15171/mejdd.2019.138.

\section{INTRODUCTION}

A 32-year old woman came to the outpatient gastrointestinal clinic and complained of intermittent abdominal pain, rectal bleeding, straining, and a sense of incomplete evacuation. She did not notice any involuntary weight loss. There was no personal and family history of colorectal cancer and other bowel diseases. She was worried about her diagnosis. What should be done for evaluation and management?

Cruveihier first described unfamiliar cases of rectal lesions in a series of patients in 1820 s and a more than a century later, the term "solitary ulcer of the rectum" was introduced in the medical literature. ${ }^{1,2}$ Now a renowned medical condition, solitary rectal ulcer syndrome (SRUS) is a chronic infrequent disorder in gastroenterology. Its exact prevalence is not clearly known but a figure of 1:100,000 per year is usually reported ${ }^{3-5}$ and there seems to be no sexual or age preference. ${ }^{6-8}$

The syndrome is characterized by painful and difficult defecation, a sense of incomplete evacuation, and sometimes lower gastrointestinal bleeding. ${ }^{9}$ Although the term may be misleading, patients with SRUS do not necessarily have ulcers and if present, they are not confined to the rectal mucosa and may differ in size and form, from a patchy erythematous lesion to polyps, and well-developed ulcers. ${ }^{8} 10$ Hence, it is the combination of endoscopic findings, histologic properties and patients' complaints that will lead physicians to the diagnosis of SRUS. 
The vague definition of SRUS, its wide range of endoscopic findings and overlapping symptoms, make it hard to distinguish this somehow rare condition from more serious diseases such as inflammatory bowel disease. The present article will review different aspects of SRUS, providing thorough insight into the disease, which might help improving diagnosis and treatment of the condition.

\section{Pathogenesis}

The underlying mechanisms leading to SRUS are not certainly recognized. However, various factors are considered to have a role. Here we propose four main categories known to be involved. First, prolonged straining during defecation, which might end in direct trauma to the vulnerable rectal mucosa. ${ }^{11}$ Patients who have constipation or anatomical anomalies are more prone to suffer from straining and at higher risk for developing rectal ulcers. ${ }^{12}$ It is also reported that patients with solitary rectal ulcers are more likely to have increased resting and squeezing pressure than normal individuals. ${ }^{11}$ This may end in higher overall pressure burden bearded upon rectal mucosa and higher risk of traumatic injuries.

Second, direct instrumentation or digital trauma inflicted by patients as a mean to take out impacted fecal material will lead to traumatic injuries to rectum. ${ }^{6,13}$ This is far more common, if not limited to patients suffering from constipation. Though reasonable, this can't be the only contributing factor since there are reports of patients having lesions much further than a finger can reach.

Disorganized contraction of puborectalis muscle in response to attempt on defecation is a well-proposed etiology, which result in higher pressures in anorectal area. ${ }^{3,6}$ During defecation, the perineum would descend to straighten the canal. Inappropriate puborectalis contraction during this process or defecation in squatting position will lead to traumatic compression of rectal wall against anal canal. On the other hand, the contradictory force of this paradoxical movement causes mucosal ischemia and renders the area more susceptible to traumatic injury and ulceration. ${ }^{6,14,15,16}$

The excessive pressure generated as the aggregate result of constipation, straining and puborectalis aberrant contraction may end in rectal prolapse and intussusception in the long run. Even the first tiny areas of intussusception can cause vascular injury and further compromise blood supply of the mucosa, which is the last part of ulcer formation and development. ${ }^{17,18}$

Apart from these explanations, some unknown factors may also be involved. For example, there is a case report of a solitary rectal ulcer in a woman resolving during pregnancy and recurring after delivery, which may point to a hormonal factor. ${ }^{19}$ Failure of corrective surgery to resolve symptoms of SRUS brings about another uncertainty in understanding possible factors involved in the pathogenesis of this condition..$^{20}$ Overall, it seems that chronic mucosal injury and ischemic trauma are the main mechanisms though further studies may shed more light on the process.

\section{Clinical presentation}

Solitary rectal ulcer syndrome (SRUS) may typically present with anal pain, rectal bleeding and constipation. Accompanying symptoms also include tenesmus, excessive straining during defecation, mucus discharge, pelvic discomfort and incomplete evacuation. ${ }^{6,12} \mathrm{Up}$ to one fourth of the patients may be asymptomatic. ${ }^{8}$ More than half of patients suffer from constipation; however diarrhea is seen in $20-40 \%{ }^{21}$

The most common symptom is rectal bleeding, the amount of which is different according to patients' condition. Hematochezia may range from blood streaks over stool to a gross hemorrhage requiring transfusion or emergency diagnostic workup. ${ }^{22,23}$ Remained untreated, rectal prolapse would be the final presenting symptom. Psychologic problems, especially obsessive-compulsive disorder, may be present in some SRUS patients. ${ }^{24}$

SRUS, as the name would express, is usually acknowledged as a single rectal ulcer but the lesion may actually vary from an erythematous patch to multiple well-developed polyps. ${ }^{8}$ This presentation along with the various symptoms mentioned above is sometimes misleading to a diagnosis of inflammatory bowel disease and needs special attention. Digital manipulation to remove impacted stool may also cause mucosal injury and induce mucosal breaks. ${ }^{12,25}$

\section{Diagnosis}

The diagnosis of solitary rectal ulcer syndrome is based on clinical, endoscopic and histopathologic aspects. Since the two former categories are not so specific, the diagnosis should be confirmed by his- 
Table 1: Diagnostic criteria for dyssynergic defecation

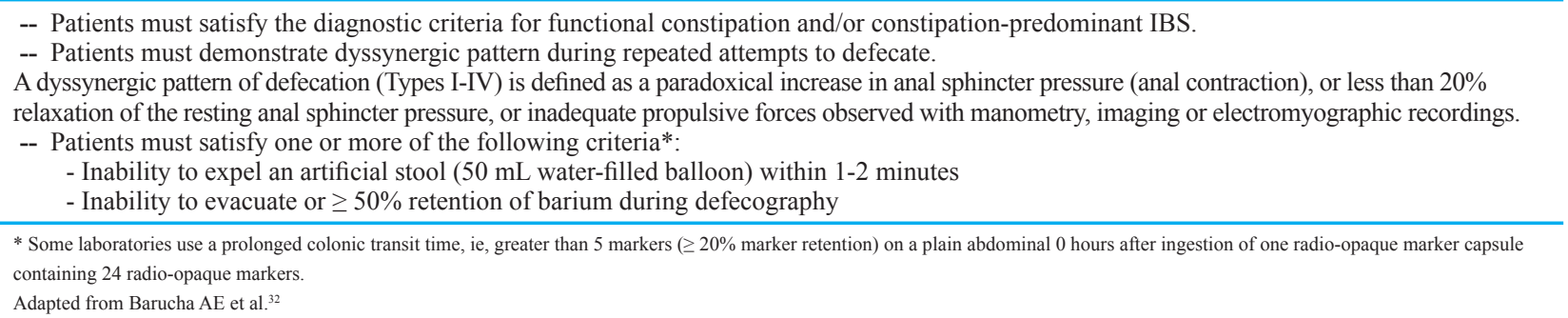

tologic findings to prevent misdiagnoses. ${ }^{26}$

\section{Endoscopy}

The endoscopic findings vary from simple mucosal erythematous patch to a solitary or multiple ulcers. However, endoscopy may also reveal non-ulcerative polypoid or mass lesions. ${ }^{4,12,27}$ Ulcers range in size from 0.5 to $4 \mathrm{~cm}$ and most of them are located on the anterior rectal wall, up to $10 \mathrm{~cm}$ from the anal verge. Rarely there might be some ulcers located in the anal canal or even the sigmoid colon. ${ }^{8,28}$

\section{Defecography}

Uncoordinated contraction of puborectalis muscle and defecation problems are one of the main aspects of SRUS. In patients with defecation disorders, defecography can detect the functional anorectal components involved in pathogenesis of SRUS. ${ }^{29}$ In one study of 43 patients with solitary rectal ulcer syndrome, only two patients had normal defecogram with the most common finding being intussusception. ${ }^{30}$ In another study, 55\% of SRUS patients had abnormal defecography including anterior or posterior rectocele, non-relaxing puborectalis muscle, prolonged contrast retention, rectal intussusception and megarectum. ${ }^{31}$

Defecation dys-synergy should be diagnosed based on three measures: Presence of constipation, inappropriate pattern of defection on manometry or electromyography, and other evidence of colorectal dysfunction including abnormal defecography, delayed metallic marker elimination or abnormal balloon expulsion test. The latest ROME-IV criteria for diagnosis of dyssynergic defecation is shown in table $1 .^{32}$

\section{Endoscopic ultrasound (EUS)}

EUS findings in patients with solitary rectal ulcer syndrome include thickening of rectal wall and internal anal sphincter as well as intussusception. Multiple submucosal cysts, hyperechogenic bands of fibrosis in the submucosal layer without disruption of the outer hypoechoic layer (muscular layer) and regional lymph node infiltration are other possible findings. Patients with SRUS and abnormal balloon expulsion test may have thicker internal anal sphincter on EUS. ${ }^{31}$ The ratio of external anal sphincter to internal anal sphincter thickness is usually reduced in patients with SRUS. ${ }^{33-35}$

\section{Histopathology}

Typical features of rectal ulcers in SRUS are fibromuscular obliteration in lamina propria along with hypertrophic and disrupted muscularis mucosa and distorted crypt structure. 9,26,36 Villiform structures are apparent in polypoid lesions and gland entrapment in submucosa is sometimes reported, a condition called colitis cystica profunda. ${ }^{37}$ Histologic findings of a study on samples from 115 patients showed superficial ulcers, cryptic distortion, and inflammatory properties in $59 \%, 17 \%$, and $33 \%$, respectively. ${ }^{36}$

The observation of collagen infiltration in lamina propria is a key feature differentiating SRUS from IBD or chronic colon ischemia. Since many malignant lesions may initially present as a single superficial ulcer or polypoid lesion, biopsies should be taken to rule out neoplastic infiltration. Though, the two might also be seen synchronously. ${ }^{38-40}$

\section{Differential diagnosis}

It is important to distinguish solitary rectal ulcer syndrome from other disorders which may have similar clinical presentations and endoscopic appearance. The differential diagnosis of SRUS includes rectal cancer, idiopathic inflammatory bowel disease, infectious diseases, rectal endometriosis, and drugs. ${ }^{8,11,41-44}$ 


\begin{tabular}{|c|l|}
\hline \multirow{2}{*}{ Presentation } & $\begin{array}{l}\text { - Minimal bright red blood per rectum } \\
\text { - Confirm history, do physical examination, consider appropriate scopy }\end{array}$ \\
\hline \multirow{2}{*}{ Scopy } & $\begin{array}{l}\text { - Solitary rectal ulcer } \\
\text { - Confirm histology and rule-out other pathologies }\end{array}$ \\
\hline \multirow{2}{*}{ Early action } & $\begin{array}{l}\text { - Multidiemsional managent } \\
\text { - Reassurence, digitation behavior avoidance, phychologic evaluation,medical management of } \\
\text { ulcer and constipation }\end{array}$ \\
\hline \multirow{2}{*}{$\begin{array}{l}\text { Refractory } \\
\text { constipation }\end{array}$} & $\begin{array}{l}\text { - Dyssynergic defeacation } \\
\text { - Clinical evaluation including history and baloon expulsion test, biofeedback modalities }\end{array}$ \\
\hline \multirow{2}{*}{$\begin{array}{l}\text { Refractory } \\
\text { bleeding }\end{array}$} & $\begin{array}{l}\text { - Remnat Ulcer } \\
\text { - Confirmation by scopy, consider differential diagnosis for rectal bleeding and evaluate psychological } \\
\text { status, radiologic evaluation for background etiology including mucosal prolapse and rectocele }\end{array}$ \\
\hline \multirow{2}{*}{ Intervention } & $\begin{array}{l}\text { - Tertiary care } \\
\text { - Multi-disciplinary team decision making to select local endoscopic versus surgical treatemnts }\end{array}$ \\
\hline
\end{tabular}

Fig.1: Proposed clinical pathway for management of a patient with SRUS

\section{Treatment}

Treatment of SRUS is based on pathophysiology, the severity of symptoms, type of SRUS and presence of rectal prolapse. ${ }^{5,26}$ Patient education and behavior modification are the first and main steps in the treatment of SRUS. Behavior therapy such us biofeedback therapy (BFT) teach how you can relax your pelvic floor muscles and external anal sphincter (EAS) during bowel movement. ${ }^{28}$

Asymptomatic patients benefit from BFT and lifestyle changes. These may include high-fiber diet, drinking enough water (non-carbonated and caffeine-free beverages) during the day, regulation of toilet time, treatment of psychological problems and prevention of straining and anal digitation. ${ }^{45}$ BFT and lifestyle changes in combination with stool softeners and bulks laxatives may help patients with mild to moderate symptoms without significant rectal mucosal prolapse. ${ }^{46}$ Jarrett and colleagues found that $12 / 16(75 \%)$ of patients with SRUS had subjective improvement and endoscopic healing after BFT. ${ }^{47}$

Improvement of clinical symptoms do not mean endoscopic healing. ${ }^{48}$ People with more severe signs and symptoms may require medical or surgical treatment. Topical treatments such as sucralfate, 5-ASA, sulfasalazine, and corticosteroid enema have been reported to be effective by reducing inflammation and preventing irritant injury. ${ }^{49-52}$ More controlled studies and long-term follow up are needed to con- firm topical agent effects on ulcer healing.

Surgery is recommended for refractory cases of SRUS despite lifestyle changes and medical treatment or for the patient with full thickness rectal mucosal prolapse. ${ }^{53}$ There are multiple types of SRUS surgery. Rectal prolapse surgery (rectopexy procedure), surgery to remove the ulcer (Delorme procedure) or rectal excision (Altemeier perineal proctectomy). Patients with paradoxical rectal spasm (PRS) and complete internal prolapse were treated by stapled transanal local excision (STARR). Diversion colostomy is used in patients who have failed other surgical methods. ${ }^{11}$ Careful patient selection for surgery is extremely important and cannot be overemphasized. Most patients do not benefit from surgery and sending the inappropriate patient to surgery may lead to catastrophes.

Scleratherapy by injection into the submucosa or retro rectal space with 5\% phenol, 30\% hypertonic saline or $25 \%$ glucose and perianal cerclage has been also reported to be effective in some patients with rectal prolapse. ${ }^{54}$ Endoscopic application of human fibrin sealant is useful in the treatment of SRUS. ${ }^{55}$ Therapeutic transcutaneous needle injection of botulinum toxin into the external anal sphincter (EAS) is a novel treatment for difficult defecation and anal fissure and may help to resolve pathophysiology of SRUS. ${ }^{56}$

A summary of a proposed clinical pathway for management of a patients with SRUS is depicted in figure 1 . 


\section{Case management}

No abnormal finding was found in abdominal examination. Digital rectal examination was done with local anesthetics and no mass lesion was detected. Total colonoscopy was performed which revealed normal rectal mucosa and a $1.5 \times 1.3 \mathrm{~cm}$ ulcerative polypoid lesion was seen in the anterior wall of rectum approximately $9 \mathrm{~cm}$ from anal verge. Multiple biopsies were taken.

Histopathology report showed superficial mucosal hemorrhage with fibroblasts and smooth muscle obliterating the lamina propria. Edema and thickening of the muscularis mucosa was also present. No evidence of dysplasia or malignancy reported. All of these characterized a case of SRUS.

Bulk laxatives were started and the patient was advised to follow a high fibre diet with plenty of fluid consumption. Six sessions of biofeedback therapy was scheduled and trestment with 5-ASA was also initiated. She returned to the clinic after 3 months with no improvement in her symptoms. Thus, she was referred to a gastrointestinal surgeon who requested an anorectal manometry. Dyssynergic contraction of the puborectalis muscle compatible with type 4 dyssynergic pattern of defecation was evident in manometry and she underwent surgery using Delorme procedure.

Her post-operative care was ordinary and she was sent home with emphasis on continuing dietary modifications to avoid excessive strain during defecation. There was no complaint in the 3-month follow-up visit and the ulcer was healed in sigmoidoscopy.

\section{ETHICAL APPROVAL}

There is nothing to be declared.

\section{CONFLICT OF INTEREST}

The authors declare no conflict of interest related to this work.

\section{REFERENCES}

1. Felt-Bersma RJ, Tiersma ES, Cuesta MA. Rectal prolapse, rectal intussusception, rectocele, solitary rectal ulcer syndrome, and enterocele. Gastroenterol Clin North Am 2008;37:645-668,ix. doi:10.1016/j.gtc.2008.06.001.

2. Cruveihier J. Ulcer chronique du rectum. In: Bailliere JB. Anatomie pathologique du crops humain. Paris 1829.

3. Morio O, Meurette G, Desfourneaux V, D'Halluin PN, Bretagne JF, Siproudhis L. Anorectal physiology in solitary ulcer syndrome: a case-matched series. Dis Colon Rectum 2005;48:1917-
22. doi:10.1007/s10350-005-0105-x.

4. Martin CJ, Parks TG, Biggart JD. Solitary rectal ulcer syndrome in Northern Ireland 1971-1980. Br J Surg 1981;68:7447. doi:10.1002/bjs. 1800681021.

5. Forootan M, Darvishi M. Solitary rectal ulcer syndrome: A systematic review. Medicine 2018;97:e0565. doi:10.1097/ md.0000000000010565.

6. Latos W, Kawczyk-Krupka A, Ledwo n A, Sieroń-Stołtny K, Sieroń A. Solitary rectal ulcer syndrome: the role of autofluorescence colonoscopy. Photodiagnosis Photodyn Ther 2007;4:179-83. doi:10.1016/j.pdpdt.2007.03.002.

7. Dehghani SM, Haghighat M, Imanieh MH, Geramizadeh B.Solitary rectal ulcer syndrome in children: a prospective study of cases from southern Iran. Eur J Gastroenterol Hepatol 2008;20:93-5. doi:10.1097/meg.0b013e3282f1 cbb6.

8. Tjandra JJ, Fazio VW, Church JM, Lavery IC, Oakley JR, Milsom JW. Clinical conundrum of solitary rectal ulcer. Dis Colon Rectum 1992;35:227-34. doi:10.1007/bf02051012.

9. Madigan MR, Morson BC. Solitary ulcer of the rectum. Gut 1969;10:871-81. doi:10.1136/gut.10.11.871.

10. Marchal F, Bresler L, Brunaud L, Adler S, Sebbag H, Tortuyaux JM, et al. Solitary rectal ulcer syndrome: a series of 13 patients operated with a mean follow-up of 4.5 years. Int J Colorectal Dis 2001;16:228-33. doi:10.1007/s003840100303.

11. Sharara AI, Azar C, Amr SS, Haddad M, Eloubeidi MA. Solitary rectal ulcer syndrome: endoscopic spectrum and review of the literature. Gastrointest Endosc 2005;62:755-62. doi:10.1016/j.gie.2005.07.016.

12. Blackburn C, McDermott M, Bourke B. Clinical presentation of and outcome for solitary rectal ulcer syndrome in children. J Pediatr Gastroenterol Nutr 2012;54:263-5. doi:10.1097/ mpg.0b013e31823014c0.

13. Contractor TQ, Contractor QQ. Traumatic solitary rectal ulcer in Saudi Arabia. A distinct entity? J Clin Gastroenterol 1995;21:298300. doi:10.1097/00004836-199512000-00010.

14. Tandon RK, Atmakuri SP, Mehra NK, Malaviya AN, Tandon HD, Chopra P. Is solitary rectal ulcer a manifestation of a systemic disease? J Clin Gastroenterol 1990;12:286-90. doi:10.1097/00004836-199006000-00010.

15. Parks AG, Porter NH, Hardcastle J. The syndrome of the descending perineum. Proc $R$ Soc Med 1966;59:477-82. doi:10.1177/003591576605900601.

16. Rao SS, Ozturk R, De Ocampo S, Stessman M. Pathophysiology and role of biofeedback therapy in solitary rectal ulcer syndrome. Am J Gastroenterol 2006;101:613-8. doi:10.1111/ j.1572-0241.2006.00466.x.

17. Mackle EJ, Parks TG. The pathogenesis and pathophysiology of rectal prolapse and solitary rectal ulcer syndrome. Clin Gastroenterol 1986;15:985-1002.

18. Nagar AB. Isolated colonic ulcers: diagnosis and management. Curr Gastroenterol Rep 2007;9:422-8. doi:10.1007/s11894007-0053-9.

19. Sood SK, Garner JP, Amin SN. Spontaneous resolution of solitary rectal ulcer syndrome during pregnancy: report of a case. $\mathrm{Dis} \mathrm{Co}$ lon Rectum 2008;51:1149-52. doi:10.1007/s10350-008-9268-6.

20. Halligan S, Nicholls RJ, Bartram CI. Evacuation proctography in patients with solitary rectal ulcer syndrome: anatomic abnormalities and frequency of impaired emptying and prolapse. AJR Am J Roentgenol 1995;164:91-5. doi:10.2214/ajr.164.1.7998576.

21. Altamirano-barrera A, Remes Troche JM, Adame EC. Solitary rectal ulcer syndrome. Anorectal dis. doi:10.1016/B978-0-12815346-8

22. Kato K, Nagase A, Iwasaki Y, Taniguchi M. Massive bleed- 
ing from visible vessels within a solitary rectal ulcer. Surgery 2014;155:95695-7. doi:10.1016/j.surg.2012.12.006.

23. Geramizadeh B, Baghernezhad M, Jahanshani Afshar A. Solitary rectal ulcer: a literature review. Ann Colorectal Res 2015;3:e33500. doi:10.5812/acr.20749.

24. Rao SS, Seaton K, Miller MJ, Schulze K, Brown CK, Paulson J, et al. Psychological profiles and quality of life differ between patients with dyssynergia and those with slow transit constipation. J Psychosom Res 2007;63:441-9. doi: 10.1016/j. jpsychores.2007.05.016.

25. Martin de Carpi J, Vilar P, Varea V. Solitary rectal ulcer syndrome in childhood: a rare, benign, and probably misdiagnosed cause of rectal bleeding. Report of three cases. Dis Colon Rectum 2007;50:534-9. doi:10.1007/s10350-006-0720-1.

26. Zhu QC, Shen RR, Qin HL, Wang Y. Solitary rectal ulcer syndrome: clinical features, pathophysiology, diagnosis and treatment strategies. World J Gastroenterol 2014;20:738-44. doi:10.3748/wjg.v20.i3.738.

27. Blanco F, Frasson M, Flor-Lorente B, Minguez M, Esclapez P, García-Granero E. Solitary rectal ulcer: ultrasonographic and magnetic resonance imaging patterns mimicking rectal cancer. Eur J Gastroenterol Hepatol 2011;23:1262-6. doi: 10.1097/ meg.0b013e32834b0dee.

28. Ignjatovic A, Saunders BP, Harbin L, Clark S. Solitary 'rectal' ulcer syndrome in the sigmoid colon. Colorectal Dis 2010;12:1163-4. doi:10.1111/j.1463-1318.2009.02108.x.

29. Goei R, Baeten C, Janevski B, Van Engelshoven J. The solitary rectal ulcer syndrome: diagnosis with defecography. American Journal of Roentgenology 1987;149:933-6. doi:10.2214/ajr.149.5.933.

30. Mahieu PHG. Barium enema and defecography in the diagnosis and evaluation of the solitary rectal ulcer syndrome. Int $J$ Colorectal Dis 1986;1:85-90. doi:10.1007/bf01648412.

31. Sharma A, Misra A, Ghoshal UC. Fecal evacuation disorder among patients with solitary rectal ulcer syndrome: a case-control study. $J$ Neurogastroenterol Motil 2014;20:531-8. doi:10.5056/jnm14030.

32. Rao SS, Bharucha AE, Chiarioni G, Felt-Bersma R, Knowles $\mathrm{C}$, Malcolm A, et al. Functional anorectal disorders. Gastroenterology 2016;pii:S0016-5085(16)00175-X. doi:10.1053/j. gastro.2016.02.009.

33. Halligan S, Sultan A, Rottenberg G, Bartram CI. Endosonography of the anal sphincters in solitary rectal ulcer syndrome. Int $J$ Colorectal Dis 1995;10:79-82. doi: 10.1007/bf00341201.

34. Marshall M, Halligan S, Fotheringham T, Bartram C, Nicholls RJ. Predictive value of internal anal sphincter thickness for diagnosis of rectal intussusception in patients with solitary rectal ulcer syndrome. Br J Surg 2002;89:1281-5. doi:10.1046/ j.1365-2168.2002.02197.x.

35. Cola B, Cuicchi D, Dalla via B, Lecce F. Endosonographic pattern of solitary polypoid rectal ulcer. Tech Coloproctol 2005;9:71-2. doi:10.1007/s10151-005-0199-0.

36. Abid S, Khawaja A, Bhimani SA, Ahmad Z, Hamid S, Jafri W. The clinical, endoscopic and histological spectrum of the solitary rectal ulcer syndrome: a single-center experience of 116 cases. BMC Gastroenterol 2012;12:72. doi:10.1186/1471-230x-12-72.

37. Levine DS. "Solitary" rectal ulcer syndrome. Are "solitary" rectal ulcer syndrome and "localized" colitis cystica profunda analogous syndromes caused by rectal prolapse? Gastroenterology 1987;92:243-53. doi:10.1016/0016-5085(87)90868-7.

38. Li SC, Hamilton SR. Malignant tumors in the rectum simulating solitary rectal ulcer syndrome in endoscopic biopsy specimens. Am J Surg Pathol 1998;22:106-12.

39. Monkemuller KE. Solitary rectal ulcer syndrome and rectal cancer [letter]. Am J Gastroenterol 1999;94:1417. doi: 10.1097/00000478-199801000-00014.
40. Tsuchida K, Okayama N, Miyata M, Joh T, Yokoyama Y, Itoh $\mathrm{M}$,et al. Solitary rectal ulcer syndrome accompanied by submucosal invasive carcinoma. Am J Gastroenterol 1998;93:22358. doi:10.1016/s0002-9270(98)00503-6.

41. Pattullo V, Tomlinson J, Bell C. Gastrointestinal: Solitary rectal ulcer syndrome. J Gastroenterol Hepatol 2007;22:2362. doi:10.1111/j.1440-1746.2007.05231.x.

42. Gopal DV, Young C, Katon RM. Solitary rectal ulcer syndrome presenting with rectal prolapse, severe mucorrhea and eroded polypoid hyperplasia: case report and review of the literature. Can J Gastroenterol 2001;15:479-83. doi: 10.1155/2001/145041.

43. Daya D, O'Connell G, DeNardi F. Rectal endometriosis mimicking solitary rectal ulcer syndrome. Mod Pathol 1995;8:599.

44. Choi YM, Song HJ, Kim MJ. Solitary rectal ulcer syndrome mimicking rectal cancer. Ewha Med J 2016;39:28-31. doi:10.12771/emj.2016.39.1.28.

45. Malouf AJ, Vaizey CJ, Kamm MA. Results of behavioral treatment (biofeedback) for solitary rectal ulcer syndrome. Dis Colon Rectum 2001;44:72-6.

46. Badrek-Amoudi AH, Roe T, Mabey K, Carter H, Mills A, Dixon AR. Laparoscopic ventral mesh rectopexy in the management of solitary rectal ulcer syndrome: a cause for optimism? Colorectal Dis 2013;15:575-81. doi:10.1007/bf02234824.

47. Jarrett ME, Emmanuel AV, Vaizey CJ, Kamm MA. Behavioural therapy (biofeedback) for solitary rectal ulcer syndrome improves symptoms and mucosal blood flow. Gut 2004;53:368-70, doi:10.1136/gut.2003.025643.

48. Forootan M, Shekarchizadeh M, Farmanara H, Esfahani ARS, Esfahani MS. Biofeedback efficacy to improve clinical symptoms and endoscopic signs of solitary rectal ulcer syndrome. Eur J Transl Myol 2018;28:7327. doi:10.4081/ejtm.2018.7327.

49. Edden Y, Shih SS, Wexner SD. Solitary rectal ulcer syndrome and stercoral ulcers. Gastroenterol Clin North Am 2009;38:541-5. doi:10.1016/j.gtc.2009.06.010.

50. Zargar SA, Khuroo MS, Mahajan R. Sucralfate retention enemas in solitary rectal ulcer. Dis Colon Rectum 1991;34:4557. doi:10.1007/bf02049928.

51. Ederle A, Bulighin G, Orlandi PG, Pilati S. Endoscopic application of human fibrin sealant in the treatment of solitary rectal ulcer syndrome. Endoscopy 1992;24:736-7. doi: 10.1055/s-2007-1010574.

52. Derakhshani S, Pakzad M, Vafaie M, Tehrani-Tarighat S, Abdollahi M. A report of 112 cases of solitary rectal ulcer syndrome from Iran. Cent Eur J Med 2009;4:49-53. doi: 10.2478/ s11536-009-0006-9.

53. Bonnard A, Mougenot JP, Ferkdadji L, Huot O, Aigrain Y, De Lagausie P. Laparoscopic rectopexy for solitary ulcer of rectum syndrome in a child. Surg Endosc 2003;17:1156-7. doi:10.1007/s00464-002-4285-3.

54. Flum AS, Golladay ES, Teitelbaum DH. Recurrent rectal prolapse following primary surgical treatment. Pediatr Surg Int 2010;26:427-31. doi:10.1007/s00383-010-2565-x.

55. Vaizey CJ, Roy AJ, Kamm MA. Prospective evaluation of the treatment of solitary rectal ulcer syndrome with biofeedback. Gut 1997;41:817-20. doi:10.1136/gut.41.6.817.

56. Keshtgar AS, Ward HC, Sanei A, Clayden GS. Botulinum toxin, a new treatment modality for chronic idiopathic constipation in children: long-term follow-up of a double-blind randomized trial. J Pediatr Surg 2007;42:672-80. doi:10.1016/j. jpedsurg.2006.12.045. 